\title{
« Eu tamén son vella e recordo!». La fuente oral en la recuperación del pasado: reflexiones metodológicas para una historia sociocultural ${ }^{1}$
}

\author{
Xoán Xosé Jardón Pedras, María José lópez Álvarez \\ y RaÚl SoUtelo VázQuez *
}

\section{RESUMEN ABSTRACT}

Este trabajo pretende reflexionar sobre las limitaciones y posibilidades de intercambio interdisciplinar de métodos

e hipótesis de trabajo entre las diversas ciencias sociales a partir de la experiencia empirica de recopilación, elaboración y análisis de documentos personales de naturaleza cualitativa,

que nos permitan construir una Historia cultural de la vida cotidiana de

la gente corriente. Para ello hemos aplicado esta metodología a las líneas de investigación que estamos desarrollando sobre la Galicia rural de fines del siglo $x I x$ y de la primera mitad del siglo $x x$, comprobando que la reelaboración racional que hacen los entrevistados de su experiencia individual refleja su percepción
This paper intends to reflect about the limitations and posibilities of interdisciplinary exchange of methods and hipothetical research among the different social sciences. This has been done from the empirical experience of compilation, elaboration and the analysis of cualitative-natured personal documents that allow as tho build a cultural background of ordinary people's everyday life. In order to achieve it, this methodology has been aplied to the research lines that are being developed on the rural Galicia in the late $X I X$ century and first half of the $x \times c$. Whe noticed that the rational reelaboration dore by the interviewees on their own experience reflects their subjective view of the reality lived in

\footnotetext{
* Áreas de Historia Moderna y de Contemporánea, Universidade de Vigo.

Una versión preliminar fue defendida en el ill Congreso de Historia de la Antropologia y Antropologia Aplicada, organizado por el Instituto Padre Sarmiento del C.S.I.C. y el Instituto de Antropología de Barcelona, en Pontevedra del 14-16 de noviembre de 1996. Agradecemos al profesor X. M. Núñez Seixas de la Universidad de Santiago de Compostela la paciente revisión de este trabajo y sus interesantes aportaciones.
} 
subjetiva de la realidad vivida en redes $y$ espacios microsociales concretos $y$ que precisamente por ello, esos recuerdos reflejan una identidad colectiva que trasciende a la sociedad rural gallega de la época.

\section{PALABRAS CLAVE}

Historia cultural, narrador e interlocutor; Galicia rural, campesinos, costureras y caseros; documentos personales de naturaleza oral, vida cotidiana y cambio social. particular nets and microsocial spaces. This is the reason why those memories reflect a colective identity reaching the rural Galician of that time.

\section{KEY WORDS}

Cultural background, narrator and interlocutor, rural Galicia, peasants, dressmakers/seamstresses, tenants, personal documents os oral transmission, everyday life and social change.

"O pobriño está farto de nos contar esas historias e nós non temos ganas de as oir, porque non son nada agradables para escoitalas e ahora il disfruta contándoche eso"?

\section{INTRODUCCIÓN}

Las páginas que siguen, fruto de nuestra experiencia de campo recuperando la memoria oral, pretenden contribuir a la superación de los recelos corporativistas que impiden el fecundo intercambio interdisciplinar de métodos analíticos e hipótesis interpretativas entre las ciencias sociales. Es por ello que - siendo conscientes de que el conocimiento del «pasado non lexitima por si mesmo, pero tampouco o seu esquecemento nos libera do séu peso nin fai máis doado e lixeiro o salto cara adiante»compartimos la apuesta de Ramón Villares por una Historia Cultural que sea "capaz de enxergar os derregos polos que corren experiencias compartidas e utopias colectivas" que contrapesan y equilibran los proyectos de futuro ${ }^{3}$. Y es aquí donde surge una doble preocupación y necesidad. Por una parte, interrelacionar las vertientes socioculturales de la Historia y la Antropología con la Museología en pro de la concienciación y participación social en el rescate, conservación y divulgación del patrimonio et-

2 Transcripción fonética y literal de la conversación que mantuvimos con Gonzalo Rodríguez y su hija Zoráida de Freixendo (Alongos, Toén-Ourense), p. 20, Archivo Oral del Museo Etnolóxico de Ribadavia (M.E.R.); de ella extraemos también la frase que encabeza el título.

3 Cfr. Villares PAZ, R, "Introducción" (a las ponencias del Área de Historia) in Actas do Congreso Internacional da Cultura Galega. Consellería de Cultura da Xunta de Galicia, Santiago de Compostela, 1992, p. 75. 
nohistórico desde los museos, las facultades y escuelas ${ }^{4}$. Por otro lado, el conocimiento de las prácticas agropecuarias tradicionalmente desarrolladas por nuestros campesinos para maximizar los recursos de la Naturaleza sin agredirla, nos permitirá diseñar un modo de vida más ecológico y respetuoso con el medio, que sea una alternativa socialmente viable a la impersonal y alienante urbe de esta pretendida aldea global postmoderna ${ }^{5}$.

Únicamente haciendo una historia que se acerque a lo que Luís Castells ha caracterizado como "una imagen con rostro humano de la evolución histórica de la gente corriente" podremos crear un civismo crítico que sustente la construcción de futuros modelos de sociedad. Por ello, analizaremos las posibilidades historiográficas que ofrecen los documentos personales de naturaleza oral y material (fotografías, diarios, aperos, etc) que constituyen la tradición ${ }^{6}$ de los anónimos protagonistas de unas ricas historias vividas que han sido olvidadas por la Historia académica convencional. Estos testimonian unos modos de representar la realidad y de reproducirse socialmente en ella que se adaptaron con desigual fortuna al huracán de la Modernidad y hace casi una década que los epígonos de la escuela francesa nos prevenían sobre los problemas historiográficos que podía suscitar el término "memoria" por su ambiguedad, defendian que "su utilización estratégica puede ser fecunda para la renovación de la historiografía” ?.

4 Planteamiento explicitado in Gonzalez PEREz, C., "Incidencia do patrimonio etnogrático no ensino e na formación permanente da persoa" in Actas..., 1992, pp. 321-324; RODRIGUEZ BECERRA, S., "Conservación y divulgación del patrimonio etnográfico. El papel de los museos" in Actas..., 1992, pp. 313-315; Sierra RodRiguez, J. C., "Museos etnográficos. Una reflexión desde el debate sobre el patrimonio cultural" in Actas / Congreso internacional de Antropologia en Extremadura 1994. Las interrelaciones entre el historiador con el etnólogo, el sociólogo y hasta con el psicólogo social que analizan esas complejas estructuras que caracterizamos como 'mentalidades' y son siempre colectivas, ya fueron sen̆aladas en su dia por el profesor LE GoFf en "Las mentalidades. Una historia ambigua" in J. Le Goff y P. Nora (dirs.), Hacer la Historia, 3, pp. 81-98, Barcelona, Laia, 1980.

5 Una reflexión sobre la incidencia de estas problemáticas en Galicia in "Lourenzo Fernández Prieto. Labrego con ciencia», Galicia Internacional, Santiago, VII-1995, pp. 33-36. Para una perpspectiva más global resulta interesante Gonzalez dE MOLInA, M. Y SEVILLA GuzMan, E., Ecologia, campesinado e Historia. Madrid, 1993.

s Nos interesan fundamentalmente las percepciones y representaciones recuperables a través de la memoria oral, pero este material "sufre restricciones y determinaciones más rigurosas que un material escrito desde el punto de vista linguístico, cultural y social", por lo que viene constituyendo uno de los nuevos problemas de reflexión historiográfica, vid. MONIOT, H., "La historia de los pueblos sin historia» in J. Le Goff \& P. Nora (dirs.), Hacer la Historia, 1, pp. 117-134, Laia, Barcelona, 1978, en especial pp. 121-122.

Vid. Nora, P., "Memoria colectiva" in R. Chartier, J. Le Goff et alii, La nueva Historia, Bilbao, 1988, pp. 455-458. Para convertirla en objeto historiográfico-presumiendo unos resultados similares a los obtenidos por los modernistas con el estudio de las "mentalités" - hizo fortuna la diferenciación entre memoria colectiva y memoria histórica aunque los especialistas no han 


\section{DEFINICIÓN, PROBLEMAS Y PERSPECTIVAS DE LA METODOLOGIA HISTORIOGRÁFICA DE LAS FUENTES ORALES}

Con la tan festejada vuelta del sujeto y de los modos narrativos que revalorizan los documentos personales, la lógica de la disciplina en las ciencias sociales tiende desde los años ochenta hacia una etnohistoria que reconoce la funcionalidad de la historia oral para recuperar esa historia subjetiva de la vida cotidiana ${ }^{8}$. Proliferan nuevos temas con enfoques micro de la historia local que habian sido desatendidos por la historia académica convencional: los espacios y mecanismos de interacción y reproducción social en las familias y comunidades rurales, así como el comple-

alcanzado el consenso. Unos distinguen entre memoria entendida en sentido psicológico como registro efectuado en una cadena neuronal o como potencia psíquica que permite retener el pasado, y recuerdo que sería sobre todo, selección, reconstrucción y tambien "manipulación", especialmente cuando el recuerdo ansía convertirse en memoria. Véase CATANi, M., "Memoria y biografia. "Si lo contásemos no nos crerian". La lección del método de Primo Levi", Historia y Fuente Oral, 9. Barcelona, 1993, pp. 137-162. Por lo tanto, la memoria es una reconstrucción psiquica e intelectiva del pasado que garantiza su presencia con una representación selectiva hecha por un indivíduo y mediatizada por las instituciones, redes sociales, ideologías y lenguajes en los que el narrador está inmerso. $Y$ toda memoria sería colectiva, aportando el elemento esencial de identidad y percepción que el sujeto tiene de si y de la colectividad con la que comparte una representación del pasado; vid. Halbwachs, M., La Memoire Collective, Paris, P.U.F., 1968; Rousso, H., "A memória no é mais o que era", in J. Amado e M. de M. Ferreira (eds.), Usos \& Abusos da História Oral. Fundaçao Getulio Vargas, Rio de Janeiro, 1996, pp. 93-101. Portelli ha demostrado que «el hecho histórico relevante, más que el propio acontecimiento en si, es la memoria" como presión social para no olvidar, ya que el acontecimiento recordado actúa incesantemente sobre la memoria colectiva, mentras que lo vivenciado se agota en su breve duración, vid. PORTELLI, A., "Violencia, imaginación y memoria en un episodio de la guerra partisana", in J. M. Trujillano (ed), III Jornadas “Historia y Fuentes Orales". Memoria y Sociedad en la España Contemporánea, pp. 39-49. Fundación Cultural Santa Teresa, Ávila, 1993; e «Historia y memoria: La muerte de Luigi Trastulli», in Historia y Fuente Oral, 1, Barcelona, 1989, pp. 5-32. El autor emplea aquí el término memoria en el sentido en que antes hablábamos de recuerdo. Por nuestra parte, aceptamos que memoria colectiva sea el conjunto de recuerdos [in]conscientes de la expereincia vivida y/o mitificada por una colectvidad y que integran su identidad, especialmente ante las grandes transformaciones contemporáneas que abrían provocado una multiplicidad socio-profesional de memorias colectivas (vid. NORA, OC, 456-457), abriendo un fértil campo historiográfico. Pero discrepamos de la radical oposición que establece Maurice Halbwachs (oc., 1968) entre pasado aprendido (= historia) y pasado vivido (= memoria) ya que es la racionalización escrita del recuerdo lo que permite salvaguardarlo, estructurándolo en la temporalidad de Clio, tal como demostraremos más adelante.

\& Véase SAmuel, R., Historia popular y teoría socialista. Crítica, Barcelona, 1981, pp. 17 y 37. Resulta muy atractivo el concepto amplio de 'documentos personales' que engloba fuentes orales, fotografías, cartas, diarios, autobiografías y cuanta información pueda existir en los archivos familiares. Véase Aróstegul, J., La investigación histórica. Teoría y método. Crítica, Barcelona, 1996 , p. 380 . Hemos utilizado los documentos de la oralidad como complemento de la arqueología industrial en SOUTELo VAZQUEZ, R., "Construyendo la Etnohistoria del mundo rural ourensano. El complejo agroindustrial tradicional de A Ponte-Mandrás como estrategia integrada en la economia doméstica del campesinado ourensano: 1880-1970" in J. M. Santacreu Soler (ed.). Historia Contemporánea y Nuevas Fuentes. Alacant, 1995, pp. 89-98. Sobre esto véase también CALZADO, A. \& TORRES, R. C., "Las fuentes orales: una aplicación práctica en el caso de los oficios", Revista de Sociología del trabajo, 24, Madrid, 1995, pp. 29-38. 
jo mundo de sus representaciones e identificaciones colectivas; los barrios obreros con sus formas de organización, sociabilidad y protesta social; y especialmente la mujer que actúa en escenarios vertebrados por formas de dominación no clasista en las que vienen incidiendo las modernas teorias del género ${ }^{9}$.

Revalorizadas las biografías y memorias de vida como documentación historiable, el eclecticismo que impera en las tendencias (neo)narrativas - carentes por lo general de la reflexión e interpretación que se suponen consustanciales a las Ciencias Humanas- hace necesario apostar por una historiografía sustentada en el trabajo de campo, paralelo a la investigación en bibliotecas y archivos, para recuperar desde la perspectiva multidisciplinar de una microhistoria sociocultural ${ }^{10}$, las estrategias cotidianas de adaptación económica (mercantilización y pluriactividad) y respuesta político-social de los grupos domésticos campesinos ante un Estado y un Mercado urbano-capitalista que pretendían subordinarles en lo económico y dominarles en la esfera de lo político. Las investigaciones de los modernistas gallegos ${ }^{11}$ resaltan que la cultura campesina gallega preservó formas colectivas de gestión (en el triple nivel de propiedad, usufructo y apropiación diferencial del trabajo), capaces de tejer redes intangibles de amistad y contraprestaciones dadas/esperadas entre las familias vecinas de una misma localidad 12 .

- Para comprobar la falta de estudios sobre la mujer campesina en la historiografía española reciente véanse BUENO, M." L., "Reflexiones en torno a la historia de las mujeres, ¿una historia coyuntural?", in C. Barros (ed.), A Historia a debate, el retorno del sujeto, vol. II, Santiago de Compostela, 1995, pp. 285-297; NASH, M., “Dos décadas de historia de las mujeres en España. Una reconsideración", Historia Social, 9, Valencia, 1991, pp. 137-161; SEgurA, C., "Algunas cuestiones a debatir sobre la historia de las mujeres", in C. Barros, oc. pp. 299-304.

to Dos excelentes reflexiones sobre los nuevos enfoques y metodologías de la microhistoria in CAunCE, S., Oral History and the Local Historian, Longman Group, Londres, 1994; JuANA, J. DE, “la Historia regional y local" in J. De Juana \& X. Castro (eds.), Novas fontes, renovadas historias. VII Xornadas de Historia de Galicia, Ourense, 1993, pp. 11-23. Sobre la debilidad teórica de esta práctica historiográfica tan en boga y la urgencia de una reconceptualización que la libere del cómodo y aproblemático retorno del sujeto, sin cerrarse en los claustrofóbicos enfoques antropológicos que sobrerritualizan a las prácticas culturales cotidianas, ha incidido GrACIA CÁRCAMO, J. (1995): "Microsociología e historia de lo cotidiano» in L. Castells (ed.): La Historia de la vida cotidiana. Ayer, 19, Madrid, 1995, pp. 189-222, en especial pp. 198-202 e 219-221.

11 Por el acertado planteamiento de fuentes, métodos e hipótesis, resulta imprescindible la amena aportación de SAAVEORA, P., "La vida cotidiana en la periferia de la civilización: los campesinos de Galicia en los ss. XvII-XIX» in L. Castells (ed.), oc. pp. 101-133. Del mismo autor, La vida cotidiana en el Antiguo Régimen, Crítica, Barcelona, 1994. La fortaleza de las relaciones vecinales de solidaridad con un componente económico (albaceas testamentarios) está demostrada in Pérez Garcia, J. M., Estructuras familiares, prácticas hereditarias y reproducción social en la Vega Baja del Esla, pr. ms.

12 El predominio de lo rural y la ausencia de grandes ciudades en la configuración espacio-habitacional de Galicia la convierten en un locus ideal para el estudio de lo local en su variedad his- 
Tenemos presente que "analitzar el tema del canvi en el món rural és molt dificil, ja que les innovacions i les continuïtats sencavalquen diacrònicament (...) i encara és més dificil tractar-lo en realitats que, com la gallega, la irlandesa o la del Mezzogiorno, sembla que pertanyn al domini de les societats inmutables (...) Tant modernització com canvi social són termes susceptibles de diferents interpretacións" ${ }^{13}$, lo que ha originado la errónea equiparación de modernización con progreso económico, entendido unidireccionalmente como desarrollo del capitalismo ${ }^{14}$. En este sentido, aplicar las fuentes orales en las investigaciones que estamos desarrollando sobre el mundo rural ourensano, nos permitirá reflexionar sobre las aportaciones y limitaciones que ofrece la compleja metodología de creación, análisis y utilización de las narrativas orales ${ }^{15} \mathrm{como}$ documentos empíricos para contrastar algunas aportaciones teórico-interpretativas que se erigen en estados de la cuestión con nuestra propia observación participante/oyente en la reelaboración racional de una

tórica y socioantropológica. La aldea, la parroquia y la bisbarra o comarca, constituyen unidades espaciales integradas en las que la intensidad y funcionalidad de las relaciones sociales están garantizadas por una conformación multisecular que convirte 'lo local' en un elemento orgánico de sociabilidad definido alrededor de la parroquia y la bisbarra, por ser "una estructura social, una comunidad que se adscribe vitalmente a un espacio y que tiene consciencia de esa integración". Vid. BarReiro FERnANDEZ, X. R., "Historiografía de la historia local gallega» in Aguirreazkuenaga \& Urquijo (eds.), Perspectivas de Historia local: Galicia y Portugal. Bilbao, 1996, pp. 51-71, en especial pp. 52-53.

13 Fernandez Prieto, L., "Transformacións agràries i canvi social en la Galicia rural contemporània" in Estudis D'Historia Agrària, 10. Barcelona, 1994, pp. 5-25. Cfr. pp. 5-6. Como demostración palmaria de esto véase CARDESIN DIAZ, J. M M $^{a}$, Tierra, trabajo y reproducción social en una aldea gallega: siglos Xvil-xx. Muerte de unos, vida de otros. Ministerio de Agricultura, Madrid, 1992.

14 Rechazamos las teorías de la modernización como paradigma interpretativo ya que ignora la existencia de múltiples agriculturas y sociedades rurales en el Estado español contemporáneo. Sin embargo resulta acertado definirla como cel proceso de introducción de cambios técnicos que transforman la agricultura. Dedicando especial atención a los efectos de las alteraciones en los precios relativos de los factores primarios e intermediarios como impulsores del cambio renovador", vid. SAN JUAN MESONADA, c., "Capitalización y modernización de la agricultura española" in J. M. Sumpsi Viñas (coord.), Modernización y cambio estructural en la agricultura española, Madrid, 1994, pp. 127-169; item CARDESIN, oc., 1992, pp. 324-325.

15 Sobre las técnicas y procedimientos para crear la fuente y la relación que se establece entre los nuevos sujetos reales que concretizan la Historia y el investigador que en ese proceso de reconstrucción de una "historia viva" se convierte en historiador, vid. ACEVES LOZANO, J. E., "Prácticas y estilos de investigación en la historia oral contemporánea" in Historia Y Fuente Oral, 12. Barcelona, 1994, pp. 143-150; BERG, M., "La entrevista como método de producción de conocimientos" in Historia y Fuente Oral, 4. Barcelona, 1990, pp. 5-10; DunAwAY, D. K., "La grabación de campo en la Historia oral" in Historia y Fuente Oral, 4, pp. 63-78; HAMMER, D. \& WILDAVSKY, A., "La entrevista semiestructurada de final abierto. Aproximación a una guía operativa" in Historia $y$ Fuente Oral, 4, pp. 23-61; JoutARD, P., "El tratamiento del documento oral» in Debats 10. Valencia, 1984, pp.72-87; PedRo, J. M. \& RAMOS FloRES, M. B., "Historia, experiencia, narrativa" in $R e$ vista Catarinense de Historia, 3, Brasil, 1995, pp. 29-34; o el clásico de Pilar Folguera, Cómo se hace historia oral. Madrid, Eudema, 1994. 
experiencia vivida a nivel micro e individual por la persona que constituimos en fuente.

La llamada Historia Oral es una actividad historiográfica que comprende unas determinadas técnicas y métodos de acceso al pasado para elaborar discursos sobre temáticas específicas del tiempo presente, salvando la imposibilidad generalizada en la historiografía para construir los propios documentos ${ }^{16}$. Los condicionantes de la situación psicológica y sociológica en la que se recupera la memoria oral y los ricos inconvenientes de su naturaleza pusieron en cuestión su status, motivando reticencias como las de Julio Aróstegui cuando incide en el "necesario rigor en la recolección y acopio de los testimonios (...) para objetivizar la Historia Oral", depurando las [auto]censuras y subjetividades que relativizan su representatividad ${ }^{17}$.

Defendemos que la historia con fuentes orales es la metodología que permite vincular la práctica interdisciplinar de campo con la reflexión teórica que trasciende a la disciplina historiográfica como un todo, demostrando que el conocimiento histórico resulta siempre de una elaboración intelectual de las irreductibles experiencias del sujeto. En este caso, la producción de documentos es el resultado singular del diálogo provocado y de la original relación que se establece entre historiador y narrador que actúa como medium para recuperar el objeto de estudio. Ambos son contemporáneos y comparten unas categorías y referentes identitarios que se expresan en entrevistas legitimadas como fuentes por su valor informativo o simbólico de una visión individual que trasciende a la interpretación global de la sociedad. Estamos ante archivos provocados a posteriori que no son objetivos - ¿que documentación lo es? - y pueden recuperar recuerdos transformados en función de acontecimientos y comportamientos ulteriores, lo que lejos de ser una tara, abre infinitas posibilidades para la historia sociocultural ${ }^{18}$.

16 La Historia Oral aplicada como técnica in: JOUTARD, Ph., Esas voces que nos llegan del pasado, F.C.E., México, 1986; Roger, W., "Notes on oral History" in International Journal of Oral History, 7 (I), feb-1986, pp. 23-28. Como disciplina o especialidad individualizada dentro de la Historia, la defienden THOMPSON, P., La voz del pasado. Historia oral. Eds. Alfons el Magnánim, Valencia, 1978; y MikKA, 1., "Wat on Earth is Oral History?", in J. K. Elliot (ed), New Trails in History, Australian Press, Sidney, 1988, pp. 124-136.

ARÓSTEGUI, OC., 1995, pp. 378 y 380 . Para profundizar en estos problemas, vid. Fraser, R., "La historia oral como historia desde abajo", in P. Ruiz Torres (ed.), La Historiografia, Ayer, 12 , Madrid, 1993; Prins, G., «Historia Oral» in P. Burke (ed.), Formas de hacer historia, Alianza Editorial, Madrid, 1991. Aportación que aparece tambien en Historia y Fuente Oral, 9: Historia y Etnología, Barcelona, 1993, pp. 21-43.

18 BECKER, J. J., "Le handicap de l'a posteriori", Les Cahiers de L'IHTP, 4, París, juin-1987, pp. 95-97. Entrevistando a los emigrantes españoles que participan en la Sociedade Hispano Bra- 
A propósito de la biografía, se ha aseverado que constituye el campo idóneo para verificar hipótesis sobre las prácticas y el funcionamento efectivo de las leyes y reglas sociales, como canal privilegiado que transmite a la historiografía las técnicas peculiares de la literatura. En la biografía se demuestra la singularidad irreductible y la libertad de elección consciente del indivíduo, ya que a pesar de las limitaciones culturales, sociales y económicas que imponen, "ninguno de los sistemas normativos está lo suficientemente estructurado como para eliminar cualquier posibilidad de elección consciente, de manipulación o de interpretación de las reglas de negociación por la personas " ${ }^{19}$. Se introduce así una doble subjetividad ${ }^{20}$ que nos permite comprender la articulación entre las percepciones y representaciones de los actores con las determinaciones e interacciones de los agregados sociales, situándonos ante algo más que una ciencia auxiliar de la historia como pueden ser la Arqueología o la Demografía Histórica. Estas pueden suscitar nuevos objetos a historiar desde complejas técnicas de análisis, pero son incapaces de crear una nueva documentación, ni de mantener la enriquecedora negociación provocada por la interferencia del investigador en la vida cotidiana de la persona a la que pretende convertir en fuente.

sileira de Sâo Paulo, percibimos esta reelaboración consciente del hecho cuando nuestros colaboradores insistian en demostrarnos su antifranquismo militante o el caracter de "emigración técnica",cuestiones que están siendo debatidas por los especialistas y que han provocado la recreación a posteriori en la memoria. Quienes trabajamos con documentación oral, no siempre sabemos mantener la distancia cínica respecto de la fuente en el momento de interpretarla, evitando caer en el fetichismo de la narración ni convertirla en ficción fruto de textualizaciones arbitrarias en virtud de los intereses del investigador. Véase como desacertado ejemplo de estos errores Castanheira Gattaz, A., Braços da Resistencia. Uma História Oral da Imigraçao Espanhola, Sâo Paulo, 1996.

19 LEVI, G., "Usos da Biografía" in Amado \& Ferreira (orgs.), op. cit, 1996, pp. 167-182, (traducción de «Les usages de la biographie», Annales, 1325-1326, París, nov/dec.-1989), cfr. pp. 179-180. Sobre la revalorización de las [auto]biografías y memorias de vida como representación cualitativas de una experiencia colectiva que refleja una percepción del mundo véanse tambien: Bourdieu, P., "L'iliusion biographique», Actes de la Recherche en Sciences Sociales, 62-63, París, juin-1986, pp. 69-72; ROSENTHAL, G., “La estructura y la 'gestalt' de las autobiografias y sus consecuencias metodológicas". Historia y Fuente Oral, 5, Barcelona, 1991, pp. 105-110.

20 Reconocer esta realidad no supone renunciar a abordarla cientificamente, basándonos en la depuración, controntación con otras fuentes y en la adopción de una perspectiva de investigación sistemática, por el contrario, certifica el origen de ese espiritu crítico. Cfr. BorRas, J. M., Historia, Fuente y Archivo Oral, Madrid, 1990, en especial pp. 99-100; JouraRD, Ph., "L'Histoire Orale: bilan d'un quart de siécle de réflexion methodologique et de travaux", ponencia presentada en el XVIII Congres International des Sciences Historiques, Montreal, 1995; recogida in Amado \& Ferreira, oc., Rio de Janeiro, 1995, pp. 43-62 y en Historia, Antropología y Fuentes Orales, 15. Barcelona, 1996, pp. 155-170. 


\section{LAS NARRACIONES ORALES COMO REPRESENTACIÓN DE LA EXPERIENCIA VIVIDA POR INDIVIDUOS Y AGREGADOS SOCIALES EN LA GALICIA RURAL}

Decididos a recuperar la voz de los que nunca hablaron en un discurso histórico construido con fuentes orales, debemos seleccionar la fuente: ¿a quién entrevistar?, ¿como tomar contacto? Asumiendo que un informante de talento aporta más que diez mediocres y la doble sujección de la fuente oral a la ley de rendimientos decrecientes - por desmoralización del investigador y agotamiento del informante- la experiencia de campo nos indica que la comunidad se encarga de indicarnos a sus narradores oficiales y que resultan potencialmente tan entrevistables los individuos pertenecientes a las élites como los anónimos protagonistas de una anodina historia de vida. Constituida en fuente histórica con la llegada del investigador, la persona crea un discurso de naturaleza narrativa fruto de su experiencia vivida y aquél lo fija en el tiempo como documento oral a través de diversas formas de escritura (grabación, transcripción informatiza$\mathrm{da}, . .$.$) que lo introducen en la Historia.$

Ya determinados los objetivos de la investigación y preparado el cuestionario con el que organizar las entrevistas debemos ser conscientes de la utilidad potencial de toda la narración - tanto en el tema como en la forma - recogiendo memorias de vida que permiten enriquecer el repertorio de preguntas, a medida que la acumulación de transcripciones y notas sobre los documentos orales elaborados provoquen nuevas hipótesis y conclusiones a contrastar en las segundas entrevistas para plasmarlas como preguntas en los nuevos cuestionarios.

Hemos constatado que las personas que pretendemos entrevistar - victimas inconscientes del fetichismo de la letra impresa como símbolo de una cultura letrada estimada superior- insisten en negociar la construcción del discurso: nos ofrecen narrarnos primero para grabar a posteriori, unicamente el discurso oficial que nos interese. El siguiente fragmento evidencia la transformación que provocamos en la autorepresentación que tiene de su status la persona a partir del momento en que contactamos con ella para que nos ayude a construir un documento histórico, grabando y transcribiendo su memoria. La primera reacción es de sorpresa ante la repentina valorización de su experiencia vital como base material para una investigación científica ${ }^{21}$.

21 "Eu cóntolles, ¿pero esto para que o queren?. [P.2: Si, mire: esto é para logo facer un libro sobre como vivia a xente no Ribeiro]. ¿Cheos de merda e de pena e de traballo! E sin dormir", ex- 
En las segundas entrevistas a las que antes aludiamos, la persona convertida en fuente lee su narración en la transcripción que le entregamos, para completarla o matizarla. Hemos comprobado que la narración primigenia será ya punto de referencia indispensable para la fuente y se constituye en la «historia oficial de su vida». Percibimos el agotamiento de la fuente cuando el discurso se vuelve repetitivo, se estereotipa y no aporta nada nuevo. Sin embargo debemos conservar la relación de amistad que nos dará acceso a otros informantes y que puede facilitarnos la musealización de patrimonio material (fotografías, aperos y máquinas) o documental de valor etnohistórico.

Entrevistando a mujeres que ejercieron de "costureiras" a domicilio en su juventud y más tarde aportan estos recursos al matrimonio, hemos comprobado que conservan con orgullo su máquina como instrumento principal de un oficio que les dió cierta independencia económica y las liberaba de las tareas del campo. Hipnotizados ya porque «aprender 0 corte" funcionase como estrategia familiar para colocar a sus hijas en óptimas condiciones al mercado matrimonial como poseedoras de habilidades muy útiles para la futura familia, teorizamos que se trataba de un oficio de solteras que se convierte en un interesante complemento para la futura familia de la mujer casada. Las entrevistadas nos desmintieron al insistir en los escasos rendimientos pecuniarios de la costura, que por otra parte, iban parejos con su «deserción» de los trabajos en la explotación familiar ${ }^{22}$.

traido del comienzo de la entrevista con Maria González Pérez, de Sampaio de Ventosela (Ribadavia-Ourense), Arquivo Oral del M.E.R. Tan ilustrativas como las acertadas teorizaciones de Danièle VOLDMAN ("Definitions et usages", Les Cahiers de L'IHTP, 21, pp. 33-41, nov/1992) sobre este proceso, resultan las reflexiones de tres alumnos de Historia Social Contemporánea de la Facultade de Humanidades de Ourense (curso 1995-96), racionalizando su experiencia de recuperación de documentos orales:

- "A xente tampouco me sabia contestar, porque iles vian eso de preguntarlles como se cultivan os toxos unha cousa tan obvia que eu debia ser tonta perdida" (Elísabeth Garrido).

- "Dinche: "iHai esa palabra non a poñas porque eso ó mellor non o queren esi" Pensan que ten que ser un nivel superior ó que che din eles e que eso non ten importancia, que eso non me valería para nada" (María Elena Ramos).

- "Cando tes que encontrar información e buscar ós abueletes, a verdad é que non che contestan nada si non os conoces, pero si és xente conocida e aguantas un pouco, o señor está duas horas largando o que quere" (Dario Fernández).

22 "Meus irmaus foron canteiros $e$ as outras foron todas labradoras que cumprian para traballar na casa. ;A min aprendéronme porque dáballe moi bo xeito e andaba sempre facendo muñecas!. E decia miña mamá: " Vamola aprender a costureira que dalle moi bo xeito!". " Hai mamá, non a aprenda que dalle moi bo xeito para traballar! iTraballa moi ben e é lástima dela que despois as costureiras fanse moi nugallás". Aprendin cunha muller que cosia moi ben, era do pueblo da Eirexe e andábamos polas portas, o mais que saliamos era pola lglesia, polo Burguete, por Fondo de Vila, por Vilaboa e Fontao.Ela iba a Trasalba as veces, facer roupa de home; eu con ela alá 
Al enfrentarnos a la reconstrucción de los procesos de relativa modernización económica y protesta social en el campo gallego de anteguerra, la conservación casi arqueológica de la documentación convencional nos obligó a recurrir a las fuentes orales. A través de la recuperación sistemática de las memorias de vida de campesinos que compraron insumos, participaron en las luchas antiforales y anticaciquiles del agrarismo, emigraron o gestionaron como aparceros patrimonio de titularidad ajena, descubrimos múltiples aspectos de las acciones y representaciones que constituyeron su vida cotidiana y nos permitieron elaborar nuevas preguntas e hipótesis novedosas, certificando esa ampliación del campo de lo historiable que se presenta como defensa recurrente de la metodología de la H. O. ${ }^{23}$.

non iba, eu cosia todo o ano e as casas mellores de Amoeiro tíñachas eu. ¡Podiache ter a casa dos Sotelo, pero como non era do noso partido, non me quixo meu pai!.. (...) Despois fun aprender o corte a Orense e cosin en Orense (...) Ó tempo eu xa era mociña e levaba un vestido negro, como cosia levaba unhas cintas esi enrolladas e levaba duas enaguas esi por baixo [P.2: Outra cousa ,vamos a ver: os mozos a hora decasárense ou de buscar unha moza, polo feito de que Vde. fora costureira. ¿Influia en que tuvera mais mozos?] Bueno, eso non, por eso non. ¡Cada un gustáballe a súa!. Si non quererian todos vir para onda min e esi non podia ser, habia que repartir (...) iEu érache unha boa costureira!. Fixenlle unha sotana a un cura que non me acordo si tiña que ir a Vigo ou a Madrid, dixéronlle que eu cosía moi ben, entonces un día chamóume. ¡Non lla facía nadie do mundo!. Levoume oito dias a sotana, cobraba seis reás cada día. ¡Eu era das mellores que outras cobraban a pta. sabes! (...) Pero despois tuven que me botar a traballar eidos a medias, porque eu cosía moi ben pero non me daban os cartos (...) Ós nenos tróuxenos sempre moi limpos, moi ben remendadiños; un señor que estaba na vía co meu marido, decíalle: "iTu tes moi boa tapadeira que vas roto e ves sempre cosido!". Viñanche molladiños deiqui para abaixo, eu quedáballe secando os trapiños, coséndolle o pantalón e secándolle os zapatiños pro outro dia. Levantábase, acomodaba o gandiño. „Porque eu nunca quixen munghir as vacas, nunca puden mungir as vacas! (...) ¡Pero eu ós rapaces limpiños e ben cosidos trouxenos sempre!. Pódeo decir o pueblo todo (...) A máquina compréina cando tiña trece anos. ¡Díxenlles que ma levasen cando morrese, que ma enterrasen onda min!. Co cariño que lle teño, levo toda a vida con ela. No, ahora está vella e hasta está sin limpar. Inda estuven cosendo o outro dia con ela. Custou vinteún pesos, tiña eu trece anos. Porque eu aprendian a coser de doce anos e a ama tiña unha arca e ela iba as veces traballar (buscar un feixe de leña ou calquera cousa) e deixábame a min llautra que tiña elí, entonces vimos unha máquina metida dentro da arca. Entonces cando marchaba ela, abriamos a arca e veña, veña, dalle, dalle. ¿E para quen era?. ¡Era para minl’, transcripción de la memoria de vida de Generosa Caride Vazquez, de Parada de Amoeiro, Arquivo Oral del M.E.R., pp. 1, 3, 11 , 21 y 22; María Rodríguez Conde de A Ponte-Mandrás (San Cristobo de Cea- Ourense) recordaba que «eu antes era costureira, aprendín cunha irmá do Abellás que casou eí e despoixa andaba a coser nas casas, tería por ahi catorce anos. Eu tiña que lle pagar ela, moito non era porque que iban cobrar daquela. Eu non ganaba nada, despois empezaron a darme venticinco céntimos. iMira tu, esi nas casas por me dar algo como era unha rapaza!. Anduven por ahi de costureira hasta que me casei. Dende que casei pouco salín, porque despois logo houbo familia e o ter familia xa non é nada; non traballei para fora, asi para a familia, despois eu pouco cosín, a costura daba pouco daquela, non valia a pena".

23 Ferraroti, F., "Breve nota sobre Historia, biografia, privacy", Historia y Fuente Oral, 2, Publicaciones de la Universidad de Barcelona, 1989, pp. 51-55. Una defensa de la oralidad porque "permite obtener y desarrollar conocimientos nuevos y fundamentar análisis históricos desde la creación de fuentes inéditas o nuevas" in ACEVES, oc., p. 143. 
Los protagonistas recuerdan que asumieron "sair de caseiros» como una estrategia subordinada a la reproducción social del grupo doméstico en determinado nivel del ciclo familiar (aumento de la prole y consecuentemente, de la fuerza productiva excedentaria en la propia explotación), que permite a la postre consolidarse como "donos de seu" cuando manifiestan con orgullo que "xa solo traballábamos os nosos eidos, pero non os de nadie» ${ }^{24}$. En estos casos, el narrador intenta asegurarse de que compartimos su esquema ético, comprobando si legitimamos su actuación cuando se apropia de la madera del «pazo» que le ha «sido acasarado» para construirse la que será su vivienda familiar ${ }^{25}$.

Nos resultan especialmente interesantes, los procesos de identificación del informante con la narración de su vida y la ulterior reelaboración de ésta a partir de la historización que supone la transcripción en un documento escrito. En esta etapa de la investigación, se establece un compromiso mutuo de complicidad a partir de la asunción de lo anormal/teatral de la situación, por lo cual la fuente reconoce que "esto non o debía contar" y el investigador respeta los silencios o pregunta indirectamente, no insistiendo para no bloquearla cuando aquella demuestra desinterés por algún tema. Se ha caracterizado de hipócrita esta relación, ya que el narrador asume actuar como fuente y se compromete en la reelaboración racional pero tambien selectiva y por tanto, manipulada, de una experiencia vivida o pretendida.

Este es el ojo de la aguja que va determinar el grado de éxito en la construcción del documento oral en la medida en que seamos capaces de establecer un consenso de intereses, o por lo menos, un pacto tácito por el que, en un principio, escuchamos la narración interesada de la fuente y en contrapartida esperamos que responda a las preguntas que le formularemos después como medio para reconducir su memoria a los temas

24 Un ejemplo de utilización de las narrativas orales para acercarnos al universo de relaciones económicas y sociales que iban aparejadas a los contratos de acasaramiento por los que el arrendatario se convertía en intermediario privilegiado entre el amo ausente y la comunidad de sus vecinos, in Soutelo Vazouez, R., "Las estrategias reproductivas de la población rural. 1880-1960. Una propuesta metodológica de aproximación a la figura del caseiro gallego desde las fuentes orales", Actas de las Primeras Jornadas de Historia Económica de las Relaciones Laborales, Sevilla, nov. 1996.

25 «Eu trouxen moita madeira sin que os amos souperan nada, pero o encargado sabíao e eu pagaba. Fixémoslle a retella da casa entre eu e un cuñado, eu paguéille ó cuñado e eu tamén tiña que cobrar claro, pero díxome o Antonio que era o encargado: " Si tu buscas maneira e cobras no que sea!". Non cobraba pouco que eu cobraba a miña conciencia!. O sea que si un pau valia trinta duros poñialle vinte, era natural ¿Ou non? [P: ¡Home claro!.]. Tróuxen vigas, trouxen de todo, eu fixen a casa ca maior parte do material do pazo", transcripción de la entrevista con Gonzalo Rodriguez Pérez, de Freixendo (Alongos- Ourense), p. 66, Archivo Oral del M.E.R. 
de nuestro interés. Aquí surge un nuevo problema ya que su percepción de lo que resulta "historiable" es diferente a la nuestra. El tipo de fuente que se define como informante-colaborador, tiende a insistir en los acontecimientos que rompieron las anodinas regularidades de la cotidianidad y de sus costumbres en común, temas que él considera carentes de importancia para nosotros cuando en realidad constituyen espacios privilegiados para nuestra investigación social.

Es fundamental que el investigador sea capaz de legitimarse como interlocutor válido identificándose en los espacios físicos y de relaciones sociales vivenciados por el narrador, sea como miembro de una familia de la comunidad o como enviado de alguien conocido en ella. Hemos comprobado que ante varios investigadores, la fuente se dirige preferentemente al que ubica en su habitus socio-espacial, lo que facilita enormemente la recuperación de su memoria de vida ${ }^{26}$. En una entrevista realizada en el local de la Asociación de Veciños de Reádegos (Vilamarín-Ourense), el narrador se dirige siempre a un amigo común que nos puso en contacto; porque comparten espacios y gentes conocidas él es el interlocutor que está en situación de ratificar la veracidad del discurso de quien teoricamente es nuestra fuente, con lo que nuestra participación se reduce a contemplar como convidados de piedra una conversación entre iguales ${ }^{27}$.

26 Nuestras investigaciones en los pueblos del noroeste ourensano -tierras de las que proceden las familias de Maria José López y Raúl Soutelo- nos han permitido comprobar la utilidad de presentarnos como "hija de..." o "nieta de...", por cuanto la familia se constituye en referente básico para que la persona "entrevistable» acepte colaborar.

27 " $\mathrm{O}$ tempo habia que andar con moito coidado que habia varios grupos que andaban por ei. ¡Houbo varios! ¿Non sei si te acordas tu?, primeiro foi nun San Ramón que cando se marchaba a xente para as casas, xa ei algo de noite, pois mataran a un fulano elí ó baixar de Cambeo. Quero decir que daquelas habia lios grandes sobre esas cousas e en calquera sitio che aparecia alguén que pensaba mal de ti e que podia matarte, eso era moi facil. Eu desole logo daquelas tiña medo incluso de salir con algunha xente porque te comprometian. Houbo unha época que aquelo era malísimo. [R.2: eu inda me acordo que contara o "Pinche" que il tiña a moza en León e claro, o home veu de permiso e queria ir a León e gustábanlle moito as cartas. ¡Botar a partida gustáballe coma a un cura! Entonces foi botar a a partida e chegou esí ó oscurecer o Modesto da Blanca e dixo: “ $i$ Veña, todos para a casa!»]. Eran épocas anómalas qe pasaban casos que parecian (...) Tu ben te acordas do Caloias que é o que estamos falando, o Nabor matou a unha sra. de Bóveda eli na carretera que vai para Amoeiro. ¿Tu non sabes onde morreu? [R.2. Non, non.]. Pois morreu eli cerca de onde habia a feira do sete. ¿Non sabes? [R.2: ¿ Hai morreu en Orense?]. Si, cerca do rio. Foi onda esas fulanas que botan as cartas e con tan mala suerte que lles morreu elí. ¿Non souperas deso? [R.2: Non, non me acordo]. Pois morréulles eli. Despois movéronse e anduveron un pouco enrolladas porque claro, apareceu morto eli e habia que demsotrar como fora a cousa. Valéronse algo ca familia e a familia pasou. Todos eses Caloias, xa che digo., si por ejemplo o srto. Ile decia "jHai que matar a un fulano deses!", matábano. ¡Que non creo eu que lle mandasen matar a sra. esa de Bóveda, eso foi cousa deles!". Extraido de la transcripción de la conversación grabada con Ramón Pulido Rego, de A Ría y José Gómez Rey de Readegos (Vilamarin- Ourense), p. 33. 
Por lo tanto, demostrarle a la persona que queremos entrevistar que a través de nuestra familia o amigos tenemos un conocimiento compartido de las gentes, espacios y vivencias que conforman su universo vital es el primer paso para acceder al archivo de su memoria. El éxito de esta estrategia queda certificado cuando el entrevistado asume su papel, empieza a narrar y le concede un status diferencial a cada uno de los investigadores ${ }^{28}$. Elegido uno de los investigadores como interlocutor, el narrador le confiere el status del "Vd" y convierte a los otros en invitados de piedra. No entiende sus preguntas por la dificultad para interiorizar los cambios de registro y de intereses del entrevistador ignorado, cuando éste intenta asumir - sin éxito- la dirección de las preguntas, porque la fuente no lo legitima para ejercer la función de interlocutor que aquél pretende ${ }^{29}$.

Una de las limitaciones que más se le critican a la documentación oral, son las relativas dificultades para contextualizar la narración en el tiempo

${ }^{28}$ ¿Eu pasei moitas angustias, moitas cousas raras. ¡Metíanse conmigo! Os fascistas éranlle moi malos. ¿Vde. de onde é? [P.2: Eu son de Amoeiro e tamén habia tascistas malos]. Eli mataron ó alcalde, viñérono matar ei a retorta. De Amoeiro era a miña abuela paterna. Debia ser do centro de Amoeiro mismo (...) Eli tamén se casou un veciño noso, cunha filla dunha maestra (...) Esto éralle moi productivo, esta terra éralle moi boa. ¡Nena, a ver si me ves o bastón! ¡Bueno, pois logo vóume con Vdes.! ¿Entonces esta chica estudió contigo? (...) ¿Enton Vdes, foron os que xa estuveron falando co Gonzalo? [P.2: Si, estuvemos duas tardes con il, pero ahora queriamos que tamén nos contase Vde.j. ¡Eu bueno, eu teño moitos anos e as cousas xa se me olvidan! (...) ¡Vote viño e beba!. Non bebe. ¿Non vasea nada?. ¿E tu nena?. ;Bebe!. As miñas nenas tampouco beben nada de viño. ¿E Vde.?, ¡Bótelle ei a chical’. Extraído de la transcripción de la narración oral de Amelia González, de Alongos (Toén-Ourense). Nótese que se refiere a Isabel Puga, pariente suya que nos acompañó para localizarla, como "a nena", empleando el mismo término que evoca a sus nietas, mientras que los investigadores son "la chica" y "Vde" el que procede de una localidad castigada por las razzias falangistas en el treinta y seis y se legitima presentándose como nieto de un represaliado.

29 Porque daquela mirábase moito si habia cuñadas. ¿Non sabe? ¿Non sei si me oe a señora? [P.2: Si, si]. Si habia cuñadas ou sogra ou esi, ou moita xente na casa, as nais das fillas miraban moito eso. ¿Non sabe? ¿Entendeu Vde.? [P.2: Non, explíquenos eso mais despacio. Non lle entendín como é eso das cuñadas]. ¿Las hermanas del marido! Entonces mi padre cuando vino de Cuba se casó con mi madre. [P: ¡Fálenos en Galego que entendemos!] (...) ¡Pois que mandara il coma si fora o pai!, a nai dixolle: " BBueno, desde hoxe poste tu de reo, que fagan o que mandes tu coma si foras oamo da casa!”. ¿Entendeu? „Non entendeu a señorita!. [P.2: ¡Si, si ,si!.] (...) [P.2: ¿E seus pais porque non llo querian?] ¿Eh? [P.2: ¿Os seus pais porque non llo querian?] iNon sel que di! [P: ¿Os pais seus porqué non llo querian?] Pois non mo querian, porque el era moi bo rapaz. iPero es que el padre del matara a un hermano y es lo que me echaban siempre en cara!". Extraido de la transcripción de la entrevista mantenida con Gumersinda Alvarez Varela, de Tamallancos (Vilamarin-Ourense) en la que podemos apreciar todos estos aspectos: ruidos en la comunicación, uso de muletillas para comprobar la recepción correcta del mensaje, diferencias de tratamiento con los entrevistadores y cambios en el registro idiomático cuando cambia el interlocutor. Queda constatada asi la relación entre el idioma a emplear con el género del investigador, con situaciones vividas en espacios urbanos o con trabajos del ciclo agrícola que el narrador entiende desconocidas para el interlocutor procedente de la Universidad, paradigma de la cultura letrada y urbana. 
«¡Eu tamén son vella e recordo!». La fuente oral en la recuperación del pasado...

de la Historia dado el constante «recurso del historiador a fechar cuanto maneja [mientras que]... la tradición oral está solo muy relativamente fechada" ${ }^{30}$.

Las narrativas orales nos permiten "obtener y desarrollar conocimientos nuevos y fundamentar análisis históricos desde la creación de fuentes inéditas o nuevas" ${ }^{31}$ que poseen su propia cronología del recuerdo. En ésta los años que ocupan un espacio importante son los posteriores a la adolescencia -en los que suceden las cosas más reseñables de la vidao aquellos otros en los que la "historia de arriba" ${ }^{32}$ perturbó brutalmente el normal discurrir de la familia y del trabajo con guerras, miedos y hambres como la "longa noite de pedra" posterior al apocalíptico verano del treinta y seis. Así pues, si nos centramos en la percepción y en la interpretación que explicita la fuente, podremos fijar la temporalidad de la narración por los hechos fundacionales de la memoria (nacimiento de un hijo, matrimonio, tributo de sangre en el ejército, guerra civil, emigración,...) que marcaron su experiencia vivida. Y únicamente nos restará contrastarlo por décadas con la documentación escrita para aprehender la especificidad del sentido del tiempo en el mundo rural, en el que los ciclos reproductivos de la familia y de las diferentes labores agrícolas organizan el tiempo de larga duración de la historia. El siguiente fragmento nos demuestra que el tiempo se mide en el discurrir de la cotidianidad, solamente alterada por la entrada en tromba de la Historia en la vida del informante que sin embargo, se contradice en algunas fechas pretendidamente cruciales de su vida ${ }^{33}$.

30 MONIOT, Oc., 1978, p. 125.

3) ACEVES, OC., 1994, p. 143.

32 Vid. FrançOIS, E., "Fecondité de l'Histoire orale", Les Cahiers de L'IHTP, 4, París, pp. 3343, juín-1987, en especial p. 38.

33 "[P: ¿Entón Vde. cando e como entra en contacto cos galeguistas?]. Porque vindo do servicio militar viñeron dar unha conferencia dous ou tres: o fillo do Ramos e outro que tiña un comercio de roupas que lles chamaban os Nuñez; a min encontráronme na calle desde o pe do rio, eu iba subindo para o pueblo e entonces puxéronse a falar conmigo. Dixeronme que eles que eran galeguistas e que querian formar un centro galeguista ou unha agrupación politica para volver por Galica e esas cousas, entonces eu púxenlle un pouco de atención, viñeron varias veces e entonces eu ofrecinlle os meus servicios, que no que cabia dentro deso, que estaba disposto a coller ise camiño. E collendo eu ise camiño foi cando a fundei en Alongos que durou seis anos, hasta que nos botaron fora. [P: Claro, entón eso foi no ano trinta. ¿En que ano veu do servicio?]. Eu viñen do servicio no ano... marchei o dia, botei dous anos de servicio militar como daquela era obligación, marchei de dezanove anos ou unha cousa esi entre os dezanove e os vinte. „Marchei no ano trinta, son da quinta do trinta!. E botei dous anos (...) [P: ¿Vde, canto tempo estivo escapado?] Pois estuven durante a guerra que estallou o dezaoito e eu desde o vinte de julio estuven hasta Corpus do ano trinta e seis. [P: „Non, do ano trinta e nove!]. No, no ano... ¿No trinta e nove?... isi, no ano trinta e nove! ;Eiqui foi un desbarajuste o que fixo a Falange co pueblo que esto merecian matalos a todos! Pero non houbo maneira porque xa digo, o delegado provincial fói- 
Superado el periplo iniciático con las fuentes orales -concebidas en un principio solo como recurso accesorio para historiar el omnipresente tema de la guerra civil y la represión franquista por la carencia intencionada de la documentación "convencional»- el trabajo empírico y un cierto autodidactismo en las lecturas ${ }^{34}$ nos han permitido estructurar una metodología - tan sencilla como funcional- nucleada por el descubrimiento de cuatro necesidades:

- Fingir conocer lugares o individuos en los que el informante refuerza, ubica y legitima la narración, es un recurso que establece puentes de espacios y gentes compartidas, evitando ruidos en la comunicación. Ser «hijo/nieto o amigo de...» constituye un imprescindible punto de enganche vital con la fuente ya que nos introduce en sus redes de relaciones y lealtades sociales.

- Salvaguardar los documentos orales que elaboramos con la fuente (grabaciones, transcripciones literales y fichas de contenido de los temas tratados) para ser empleados por otros investigadores con la perspectiva de articular ya programas de documentación oral con unos criterios patronizados de organización de la entrevista, transcripción y archivo ${ }^{35}$.

- Operar en lo que se ha caracterizado como "distancia cínica del investigador». Conscientes de coprotagonizar una "parodia» con la fuente que nos habla ${ }^{36}$, no debemos creer inocentemente la «historia» que nos

nos destituir il mismo. [P: ¿Entón Vde. en que ano veu licenciado para acá?]. Pois eu marchei no ano trinta $e$ nove, viñen licenciado no corenta e dous. [P: ¿E en que ano o escolleron presidente da hermandade?]. 'Hai eso foi despois!. Desde que actuamos eiqui e desde que fixemos residencia eiqui. [P: ¿Sobre que ano seria?]. Pois podia ser si a caso, no mismo ano, certo non sei pero podia ser casi no mismo ano ou ó seguinte porque eu empecei esta casa no ano corenta ou corenta e un, cando viñen (...) No corenta e tres inaugurámola e botei dous anos facendo na casa. [R.2: ¡Botaches mais tempo papá!]. ¿Eu parécemo que botei dous anos ca casal’. Extraído de la transcripción de la memoria de vida de Gonzalo Rodriguez Pérez, de Alongos (Toén-Ourense), p. 20, Arquivo Oral del M.E.R. Interpretamos las vacilaciones en la fecha de regreso, cumplida su injusta condena, como un mecanismo inconsciente (?) de olvido; de todas maneras, resulta evidente, que el narrador fija la cronología por un dato crucial en su experiencia vivida: cuando comienza la casa y apenas es quien de temporalizar sus épocas de activista agrario-galleguista al regresar del servicio militar o las infinitas e interminables noches de "fuxido" en los montes de la comarca.

${ }^{34}$ El interés por la investigación con fuentes orales nos surgió en el equipo HISTORGA de la Facultade de Xeografia e Historia de la Universidade de Santiago y con la participación en los cursos de verano "Estrategias de colaboraçao na Raia durante a Guerra e Posguerra Espanhola: 1936-1946", organizado por Luis Martínez-Risco (Chaves-Portugal, julio de 1993) y "Contrabando, economia e emigraçao", organizado por los profesores Alberto Valín y Martínez-Risco de la Universidade de Vigo en colaboración con la Universidade de Tras-os-Montes e Alto Douro (ChavesPortugal, julio de 1994), en el que tuvimos una primera toma de contacto con los relatos de vida.

${ }_{35}$ En esta necesidad ha insistido TOURTIER-BONAzzI, Ch. de, “Archivos: propuestas metodológicas", Historia y Fuente Oral, 6, Barcelona, 1991, pp. 181-189.

36 BERG, M.: «Algunos aspectos de la entrevista como método de producción de conocimientos". Historia y Fuente Oral, 4, Barcelona,1990, vid. pp. 9-10. 
están contando, aunque sigamos escuchando de forma crítica. Si corregimos al narrador o lo cortamos para reconducirlo a nuestros temas de interés, deslegitimamos su discurso y nos arriesgamos a bloquearlo, sería tanto como levantar con excavadoras los estratos altomedievales y romanos que ocultan un asentamiento castreño, nunca sabremos qué elementos del pasado hubiéramos podido recuperar. Las experiencias de campo de Xoán Jardón en tierras de la comarca de A Limia nos demuestran la necesidad de realizar la entrevista en espacios (personas y lugares) que faciliten la recuperación de la memoria oral:

1) En una primera entrevista con José, realizada con el objetivo de recuperar la memoria de las migraciones estacionales para la siega en Castilla, mientras deambulábamos entre el instrumental de la "Sala do Agro" del Museo da Limia - al que él contribuyó con donaciones y con la propia experiencia - nos relató la función de aquellos y otros múltiples aspectos de su acontecer diario. Un imprevisto técnico destruyó parcialmente el documento grabado y cuando llevamos al entrevistado a la biblioteca del Museo para retomar el tema, se produjo una falta de comunicación entre investigador y narrador. Analizada la entrevista, consideramos que fue a consecuencia de un proceso de descontextualización al sacar a la fuente del espacio que conoce y domina por haberlo vivido. La insistencia de las preguntas obtuvo como único resultado el bloqueo de aquella, la desgana y la falta de interés por seguir con una entrevista hecha desde y para la cultura letrada que subordina a su cultura oral ${ }^{37}$. Cansados ya de teorizar sobre la capacidad adaptativa de los campesinos pluriactivos que mercantilizan sus pequeñas explotaciones domésticas y desarrollan estrategias de resistencia ante el Estado recaudador de impuestos, se hace necesario reflexionar sobre las formas de resistencia de esa cultura oral y en este caso, qué implicaciones tendría la ignorancia fingida por la persona que repentinamente decidió dejar de actuar como fuente, enfrentándonos

\footnotetext{
37 Nótese que José constituye una musealización viva de la memoria oral ya que, a veces, actua como guia de honor del Museo da Límia (Vilar de Santos-Ourense), por lo que está familiarizado con la narración en público de sus experiencias laborales; observamos tambien este contraste de actitudes entre la teatral formalidad que los vecinos del pueblo fronterizo de Cambedo (Chaves- Portugal) exhibieron en las salas del congreso; véase MARTiNEZ RISCO, L., "Contrabando, economía e emigraçâo", A Trabe de Ouro, 22, Santiago de Compostela, 1995, pp. 143-145. Compartimos la definición de la cultura oral como "un saber personalizado, distribuido entre los individuos y las especialidades que practican, donde el texto y la memoria se almacenan en las personas y en la materialidad que nos rodea y el aprendizaje se produce de manera imitativa, incorporada a los procesos de vida"; sin embargo, pensamos que se debería relativizar su subordinación por la cultura letrada de la sociedad global como espacio de lucha por el poder en el que el campesinado resiste con una estrategización conceptual perceptible en el proceso de supresión de los sistemas comunitarios de derrota de mieses en las "agras", vid. CARDESIN, oc., 1992, pp. 347-348.
} 
y tomando conciencia en el debate sobre el gran impostor y la memoria selectiva. Sin duda, el olvido es constitutivo de la memoria: lo falso, los errores o confusiones y los propios olvidos [in]voluntarios son significativos. Las construcciones imaginarias son el fruto del relato de cómo al narrador le hubiera gustado que fuese su vida. Insinuarle a la fuente que nos está mintiendo, lo pone en actitud defensiva y desestructura su memoria. Cuando el informante se convierte en actor que narra la representación de una existencia querida y no vivida sólo nos queda escuchar por respeto, recordando que pretendemos ser científicos sociales, no periodistas paparazzi y que si el documento oral no aporta datos empíricos, sus formas narrativas constituyen un material valioso para estas reflexiones metodológicas sobre la problemática de las fuentes orales.

2) Investigando con la metodología de la fuente oral la trascendencia de la concentración parcelaria en el vivir diario de los vecinos de la parroquia de Parada de Outeiro (Vilar de Santos-Ourense), observamos tambien una descontextualización «física»: las personas mayores son especialmente críticas con la nueva reordenación del territorio que les provoca la perdida del sentido del espacio, al eliminarles los referentes espaciales (riachuelos, árboles, puentes,...) de su vida. Con este proceso que representan como una más de las imposiciones del Estado al campesino, les suprimen la noción del espacio como algo cercano y compartido, fruto de la experiencia y de la memoria transmitida oralmente de una generación a otra, conformando un universo cultural en el que todo tenía desde antiguo su nombre y lugar ${ }^{38}$. Sin embargo, el paradigma de dasarraigo y per-

38 Esta idea aparece desarrollada tambien in CARDESiN, Oc., 1992, p. 347 y podemos encontrarla en el siguiente fragmento: "A parcelaria cha fai a Xunta, non hai que pedila. „Fáicha a Xunta e punto! ¿Entendes?, si non a queres voluntaria venche forzosa. Nos eiqui non sei por medio de quen veu. ¡Vantaxe non lle deu a nadie, eh! (...) Eu non a vexo ben, verana despois ben meus $f$ llos ou meus netos, pero eu nunca"; transcripción del relato de vida de Manuel Jardón y su mujer Maria Pedras, p. 36. Arquivo Oral del M.E.R. Manuel Mandianes denuncia rotundamente las consecuencias negativas de este proceso "modernizador» en la personalisima visión que nos ofrece de la concentración parcelaria en una parroquia del ayuntamiento de Os Blancos, en la comarca de A Limia: "Hai pouco tempo o goberno intentou facela concentración parcelaria. Viñeron uns enxeñeiros para explicarlles á xente as avantaxes económicas do plan e a xente entendéuno todo. Non obstante, no momento de poñer en práctica as teorias, case todos se opuxeron.(...) Os enxeñeiros e o alcalde dixeron entón que os labregos de Loureses eran "parvos" porque "non querían vivir mellor con menos traballo"; pero eles contestaron: "isto sempre estivo asi e non queremos cambiar, ¡Querían tirar coas nosas casas, corta-las árbores, facer novos camiños". Recoñecian as avantaxes, pero "se fan todo iso, despois a aldea xa non será a nosa aldea, todo será distinto". Tiveron medo de perde-los puntos de referencia. Cada anaco de terra, cada árbore, cada fonte, cada camiño é un punto de referencia, para os membros da casa e para a memoria colectiva da xente da aldea (...) Por iso podemos dicir que "a terra é a xenealoxía espacializada" da casa. Destrui-la organización espacial é destrui-la historia e a memoria da xente. Cada leira ten a súa historia, o mesmo que cada persoa e cada animal ten a súa”. Vid. MANDIANES CASTRO, M., 
«¡iEu tamén son vella e recordo!». La fuente oral en la recuperación del pasado...

dida de la memoria a consecuencia de la descontextualización espacial, lo encontramos en los ancianos recluidos en instituciones asistenciales para la tercera edad. Alumnos voluntarios realizaron en el Asilo de San José de Ourense una primera cata con una ficha elemental que nos permitiese seleccionar a los potenciales narradores para entevistarlos nosotros a posteriori. Recogemos aquí gráficamente los resultados ${ }^{39}$.

Descontextualización espacial y pérdida de la memoria

\begin{tabular}{|c|c|c|c|c|c|c|c|c|c|c|c|c|c|}
\hline \multicolumn{2}{|c|}{ EXPLORADOS } & \multirow[t]{2}{*}{1} & \multicolumn{2}{|c|}{2} & \multicolumn{3}{|c|}{3} & \multicolumn{6}{|c|}{ ENTREVISTADOS } \\
\hline & & & $A$ & $\mathrm{~B}$ & Total & A & B & Total & $E$ & $\mathrm{~B}$ & $\mathrm{R}$ & $M$ & $\mathrm{~N}$ \\
\hline Mujeres & 23 & 9 & 13 & 8 & 8 & 2 & 6 & 4 & & 1 & 1 & 1 & 1 \\
\hline Hombres & 22 & 2 & 17 & 5 & 7 & 5 & 2 & 3 & 1 & & & 1 & 1 \\
\hline Total & 45 & 11 & 30 & 13 & 15 & 7 & 8 & 7 & 1 & 1 & 1 & 2 & 2 \\
\hline
\end{tabular}

FUENTE: Realización propia a partir de fichas de exploración de entrevístables realizadas por los alumnos de Historia Social Contemporánea (curso 1995/96) con residentes en el Asilo de San José de Ourense y entrevistas da nuestra autoría.

LEYENDA:

1. Perdida de la memoria, no recuerdan su edad o fecha de nacimiento

2. Extracción socio-profesional: A) campesinos; B) otras (especialmente vendedoras)

3. Experiencia migratoria: A) campesinos; B) otras (especialmente mujeres proletarizadas como dependientas o criadas).

4. Resultados: E) excelentes; B) buenos; R) regulares; $M$ ) malos; N) nulos.

Entre los recursos empleados en el trabajo de campo con fuentes orales han merecido especial atención los cuestionarios. Nosotros optamos por acompañarnos de uno tan amplio en las propuestas temáticas como flexible en el seguimiento, que nos permita organizar la entrevista en secuencias que reconstruyan las estrategias pluriactivas de los grupos domésticos durante varias generaciones, las múltiples caras de la tradición oral y en particular, las percepciones y representaciones que conforman el universo vivienciado por las mujeres del mundo rural gallego ${ }^{40}$.

Loureses. Antropoloxia dunha parroquia galega, Galaxia, Vigo, 1984, p. 58; un acercamiento más global pero desde la rica subjetividad que resulta de la experiencia persoal, in MANDIANES CASTRO, $M$. \& Sotelo Blanco, O., A concentración parcelaria, Ed. Sotelo Blanco, Santiago de Compostela, 1994.

39 Agradecemos la excelente acogida de la comunidad de Hermanitas de Los Ancianos Desamparados del Asilo de San José de Ourense y especialmente la colaboración de sor Carmen que posibilitó este trabajo y nos permitió conocer al señor Perfecto P. I, entrañable amigo que nos brindó el tesoro de su lúcida memoria de 89 anos vividos e infelizmente nos abandonó este año. Con estas páginas queremos rendirle nuestro homenaje.

40 En esta línea de trabajo, hemos comenzado la historización a nivel micro de la maquinización agraria de anteguerra y del primer franquismo narrada por las personas que difundieron y 
Realizada la transcripción literal de la grabación, la reacción de los colaboradores delante de la fijación por escrito de su memoria nos lleva al cosmos mítico articulado desde los controles colectivos de la memoria: la comunidad crea registros comunes, para retener los hechos condicionantes del ser del individuo en los espacios de sociabilidad. Aquellos colaboradores que podríamos ubicar en la cultura oral del «labrego» no censuran la transcripción, pues estarían cuestionando la veracidad de su palabra que constituye un recurso fundamental para mantener la sanción comunitaria en las redes relacionales en las que acostumbran a moverse. Por el contrario, los individuos pertenecientes o identificados con las élites locales y que por ello participan de la cultura letrada de los grupos dominantes - vertebrada alrededor de convencionalismos y secretos compartidossí reexaminan con incómoda preocupación y minuciosidad el discurso narrado, negándose en ocasiones a seguir colaborando con nosotros.

La imagen en video y, fundamentalmente la fotografía, son fuentes susceptibles de ser empleadas como fetiche evocador y al mismo tiempo estructurador de la memoria. Actuando como un «flash-back», la imagen fotográfica refleja un momento determinado e irrepetible que facilita al informante la organización y la reconstrucción mental los hechos vividos, dotándolos de historicidad. La profesora De Sousa Andrade ha estudiado la fotografía como materialización y recuerdo de la experiencia vivida, mensaje codificado de signos proyectado a través del tiempo y que nos aporta la huella cultural de una época ${ }^{41}$.

La fotografía es el producto cultural pretendidamente objetivo de la estrategia social de producción de signos, que actúa como eficiente medio de control de los comportamientos y representaciones de los colectivos que antagonizan la dinámica social. Por otro lado, al fijar imágenes en el espacio y en el tiempo, la imagen fotográfica de un espacio vivido, articula una narrativa y un lenguaje específico que nos comunica significados (comportamientos, valores, deseos y sentimientos producidos y reproducidos), estableciendo una relación de sustitución con la realidad. Esto nos permite contrastarla con la imagen escrita, la memoria oral y las fuentes materiales para descubrir las formas de sociabilidad (pactual y conflictual)

\footnotetext{
repararon las trilladoras, arados de vertedera y otras piezas que están siendo integrados en el patrimonio cultural gallego por iniciativa del M.E.R.

41 SOUSA ANDRADE, A. M. M. DE, Sob o signo da imagem: a produçâo fotográfica e o controle dos códigos de representaçâo social da clase dominante do Rio de Janeiro na primeira metade do século XX. Tesis Doctoral defendida en la U.F.F. de Río de Janeiro en 1990. Agradecemos a la profesora Yara Khoury que nos facilitase su consulta en calidad de directora de la CEDIC en la Pontificia Universidade Católica de Sâo Paulo.
} 
y de reproducción social en las familias campesinas gallegas de este siglo. Destaca en primer lugar la oposición rural/urbano, escogiéndo uno u otro espacio en virtud del tipo de fotografía y de la funcionalidad que tenga. La experiencia de campo nos demuestra que la fotografia tenía un valor sustitutorio de los miembros del grupo doméstico que estaban emigrados, funcionando como icono para mantener viva su memoria ${ }^{42}$.

La imagen de los escolares en Vilamarín (Ourense) a comienzos de siglo y de sus coetáneos emigrados en La Habana que ofrecemos en el anexo, nos brindan una representación artificiosamente bucólica del rural donde priman la simplicidad y la indolencia, frente al progreso económico y social de la imagen de lo urbano, asociada a los valores del lujo, la riqueza y el confort típicamente burgueses ${ }^{43}$. Carecemos aún de estudios que contrapongan la información de las revistas ilustradas con las crónicas de los viajeros e incluso, con la memoria de los protagonistas de la imagen, analizando los espacios sociales y los agentes que la producen, especialmente los intereses selectivos del emisor del discurso porque la fotografía es, ante todo una reflexión del imaginario del fotógrafo. Por ello, resulta inaplazable buscar colecciones particulares en las que rastrear la existencia de imaginarios fotográficos oficiales que ocultan e intentan borrar la imagen real aportada por la documentación escrita y oral; hecho que nos invita a reflexionar sobre la existencia de una política fotográfica que sería una más de las formas de dominación de los grupos sociales instalados en el Poder.

42 "Como teño moitos fillos funllas dando e téñenas iles. Mire, istes somos nos: o meu marido e o neno que estaba con nos en Cuba; estes son os fillos máis vellos, era polo tempo da guerra, mandéilles o traxe, sacaron fotos e mandáronnos unha a nos alá, entonces nos sacamos a ampliación alá con estes dous e o pequeno que tiñamos con nos (...) Este era un primo meu que estaba en Cuba (...) Era moi corriente mandalas de Cuba pracá porque un vai cambiando, os nenos van para mozos. Este é meu fillo Pepe cando estaba en Francia e este é meu marido cando estaba no servicio cun compañeiro (...) Está é en Chantada, nos chamábamoslle "de dentro" éstas buenas e "de fora" ás que son mais ruís, cando queriamos facer unha foto boa para conservala ou para mandala fora, faciamola dentro". Extraido de la transcripción de la entrevista con Gumersinda Álvarez Varela, Arquivo Oral del M.E.R., pp. 69-70. Erosina Cudeiro nos narraba -a propósito de las fotografias enviadas por su padre en sus migraciones temporales a Cuba y en las cuales aparece con atuendo de urbánitas- que "Eu era moi pequena cando il veu, puxeron unha tiendiña e fomos marchando esi hasta que despoixa veu a guerra e no ano trinta e oito o papá morreu (...) O que tiña familia, habia costumbre de mandar fotos para Cuba e dalá praiquí, por exemplo nosas para o papá e mira que ilusión teria que inda me acordo de medirnos miña nai por un fio e mandarllo na carta para que vira o que medráramos dende que il marchara (...) Esa foto da entrada, é de meu pai de solteiro, mandáraa o papá pracá".

${ }_{43}$ La pequeña historia del hallazgo de estas fotografías nos muestra la multifuncionalidad de la metodología de la fuente oral: explorar la existencia de otros documentos personales en los archivos familiares de los entrevistados, en este caso, Ramón Pulido de A Ría, de Vilamarín (Ourense) y José Gómez Rey, de Reádegos (Vilamarín-Ourense) nos pusieron en contacto con un amigo suyo, José Blanco que había heredado de su abuelo una Memoria de la Sociedad de Instrucción Alianza de Villamarín en La Habana y nos permitió recuperarlo. 
Como conclusión, podemos afirmar que la potencialidad historiográfica de los documentos personales y especialmente las memorias de vida, radica en que su construcción y crítica sistemática, como necesario complemento de las fuentes «tradicionales" (arqueológicamente conservadas para la sociedad rural en transición), nos acerca a vívidas interpretaciones cualitativas de procesos y fenómenos histórico-sociales, fosilizados en los archivos tradicionales. Además, la recuperación de la memoria oral es el puente relacional para acceder a otra documentación de custodia particular. Al mostrarnos la memoria de la familia contenida en sus fotografías antiguas, el informante comparte con nosotros recuerdos materiales de una experiencia vivida de la que ya nos hizo copartícipes, certificando el éxito en la construcción de una relación de confianza mútua con el investigador que lo está integrando en la cultura letrada y por lo tanto, en la Historia. Sin duda las intuiciones de Pierre Nora ${ }^{44}$ se han cumplido puesto que la historización de los archivos personales como lugares de la memoria con la metodología de las fuentes orales está siendo la punta de lanza de cuantos historiadores nos preciamos de contemporaneistas. Para ser realmente "la ciencia de los hombres en el tiempo", la Historiografia debe ser tambien un arte y nada más cercano a ello que la recreación narrativa del pasado hecha por la persona que lo ha vivido y teorizada como discurso historiográfico por quienes gustamos de ser considerados científicos sociales ${ }^{45}$. Aunque a menudo olvidamos que en el proceso de recuperación del documento oral, ha sido el colaborador constituido en fuente quién contribuyó con su experiencia a nuestra formación intelectual y personal.

45 Véase en este sentido, JoutARD, Ph., op. cit., 1996, p. 221. 